\title{
EL DESAPARECIDO MONASTERIO SEVILLANO DE SAN AGUSTÍN: PLANOS INÉDITOS DEL SIGLO XIX*
}

\author{
Alberto Fernández GonzÁlez \\ Universidad de Sevilla
}

\begin{abstract}
El monasterio de San Agustín era uno de los más monumentales de Sevilla. Del histórico edificio fundado en el siglo XIII y hoy desaparecido, salvo los restos declarados Monumento Histórico-Artístico en 1964, se desconocía la distribución de su planta, que presentaba múltiples interrogantes. Este artículo da a conocer y estudia un levantamiento efectuado en 1835 por el ingeniero Benito León y Canales que documenta gráficamente la exacta compartimentación de su arquitectura. También se aportan nuevos datos y otros documentos gráficos.
\end{abstract}

Palabras clave: Monasterio de San Agustín; Sevilla; Arquitectura religiosa; Planos; siglo XIX; Benito León y Canales.

\section{THE FORMER MONASTERY OF SAINT AUGUSTINE IN SEVILLE: UNPUBLISHED $19^{\mathrm{TH}}$-CENTURY PLAN}

The Monastery of Saint Augustine was once one of the most monumental buildings in Seville. Today only the remains of this $13^{\text {th }}$-century structure exist -declared a Historic and Artistic Site in 1964-, and the distribution of the plan remained unknown until now. This article presents and analyses a plan drawn up in 1835 by the engineer Benito León y Canales, which visually documents the exact architectural divisions of the building. New data and other graphic documents are also considered.

Key words: Monastery of Saint Augustine; Seville; Religious architecture: Plans; 19th century; Benito León y Canales.

La distribución en planta del histórico monasterio sevillano de San Agustín se desconocía. No se había podido precisar porque no se había encontrado ningún documento gráfico pormenorizado que detallase la compartimentación de su arquitectura. Pero ahora, por fin, gracias a un valioso levantamiento efectuado en 1835 por el coronel ingeniero Benito León y Canales, documento recientemente hallado en el Archivo General Militar de Madrid ${ }^{1}$ (fig. 1), se puede conocer la exacta

* Este artículo se inscribe en la estancia de investigación realizada en varios archivos de Madrid durante los meses de julio y agosto de 2011, actividad que recibió una ayuda económica del Vicerrectorado de Investigación de la Universidad de Sevilla.

${ }^{1}$ Planta del convento de San Agustín extramuros de Sevilla, Archivo General Militar, Madrid (AGM), Fondo Se-7-6. 


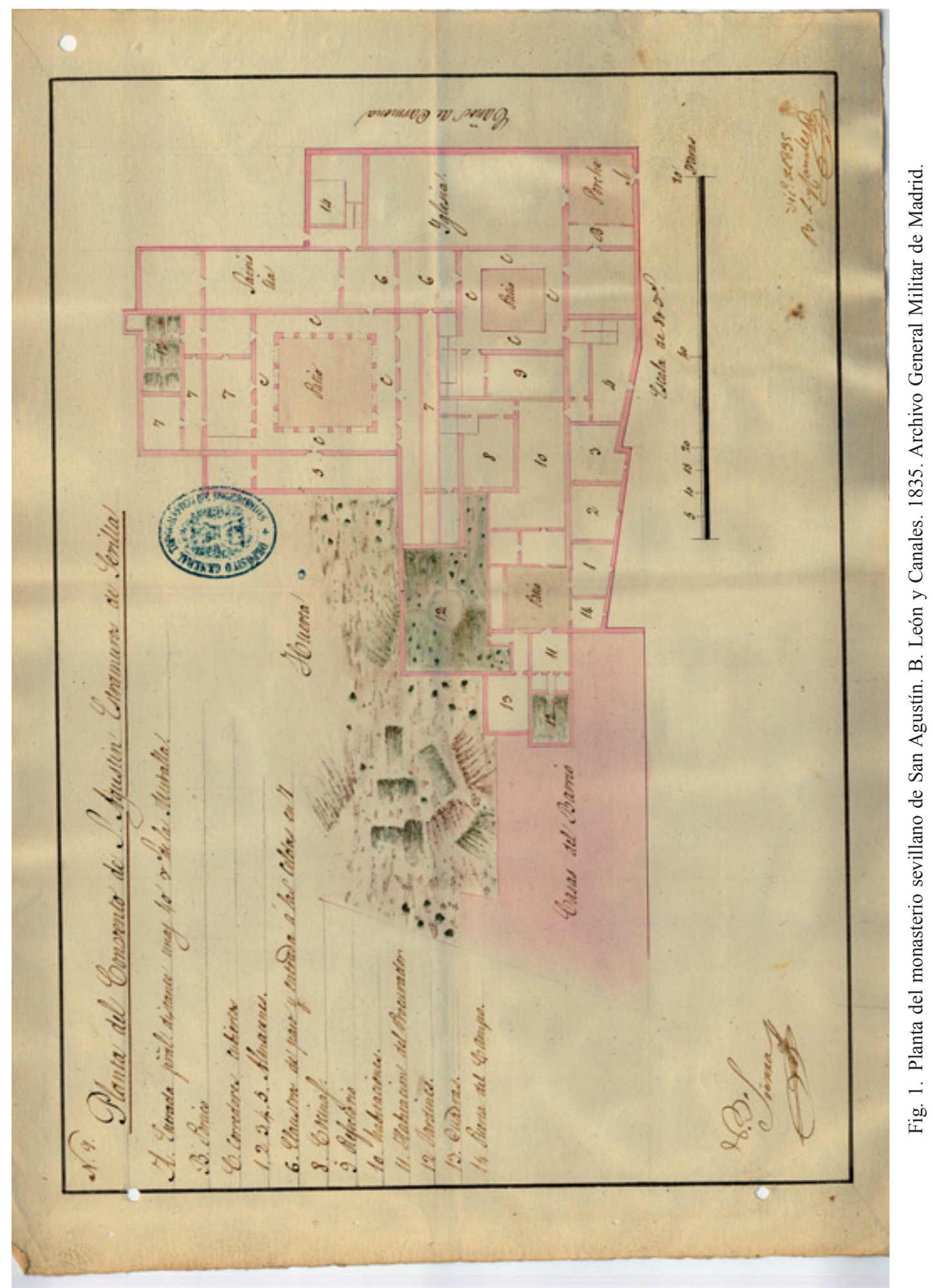

Arch. esp. arte, LXXXVI, 344, octUBRE-DICIEMBRE 2013, 311-330, ISSN: 0004-0428 
configuración interna del edificio. El plano, que fue levantado en previsión de una posible transformación del convento en cuartel, a raíz de la aplicación de los decretos de exclaustración ${ }^{2}$, es una fuente gráfica de enorme interés que describe el estado y la distribución que tenía el conjunto arquitectónico a la salida de los monjes, antes de las sucesivas remodelaciones que adaptaron los viejos espacios de la clausura a sus nuevas funciones. El trabajo de investigación se centra especialmente en el análisis de esta planta, pero también se estudian otras planimetrías parciales del edificio, alguna inédita todavía, y se aportan nuevos datos de archivo relativos a varias intervenciones arquitectónicas y urbanísticas realizadas en el convento y su entorno más inmediato a lo largo de las décadas finales del siglo XIX.

\section{El monasterio sevillano de San Agustín: breve historia}

La denominada Casa Grande de San Agustín de Sevilla era la principal de las treinta y seis que tenía la Orden en la antigua provincia de Andalucía. El monasterio se emplazaba fuera de la ciudad, frente a las murallas medievales y la Puerta de Carmona, al pie de la vía Augusta romana, un importante camino de acceso a la localidad ${ }^{3}$. El tejido urbano donde se insertaba el edificio agustino está perfectamente documentado en el famoso plano de Sevilla delineado por Francisco Coelho y grabado por Joseph Amat que mandó realizar el asistente Pablo de Olavide en 1771 (fig. 2). Siguiendo esta importante fuente gráfica se constata que la Casa Grande ocupaba una extensa área trapezoidal $\left(n^{\circ} 61\right)$ localizada en la collación de San Roque ${ }^{4}$. Al norte, donde se situaba la amplia huerta de los monjes, lindaba el monasterio con la explanada conocida como de San Agustín; al sur, con los Caños de Carmona ( $\mathrm{n}^{\circ}$ 179), el histórico acueducto que surtía de agua a una parte considerable de la ciudad; al este, con el prado de Santa Justa y el arroyo Tagarete, hoy calle de Amador de los Ríos; y al oeste, con la calle ancha de San Roque, la plaza de San Agustín, la muralla medieval y la Puerta de Carmona ( $\left.\mathrm{n}^{\circ} 13\right)$.

No se puede precisar la fecha exacta de la fundación agustina porque los cronistas y los diferentes investigadores que estudiaron la cronología de la Casa Grande o bien la sitúan en 1248, fecha de la conquista de Sevilla por Fernando $\mathrm{III}^{5}$, o la retrasan al siguiente año ${ }^{6}$, llegando incluso a datarla, no sin buenos argumentos, en $1292^{7}$. El convento se vinculó en el siglo XIV al patrocinio de la familia Carranza, que costeó la edificación de la capilla mayor, y al de Pedro Ponce de León. Las donaciones y el apoyo económico fueron aumentando con el paso del tiempo y el monasterio, ya en la Edad Moderna, llegó a ser uno de los más monumentales de Sevilla, junto con el de San Francisco, San Pablo, San Jerónimo y la Cartuja ${ }^{8}$. La llegada de los invasores franceses en febrero

${ }^{2}$ El convento quedaba suprimido en aplicación de los Reales Decretos de 25 de julio y 11 de octubre de 1835; por el de 8 de marzo de 1836, que establecía la exclaustración y desamortización general, y por la Ley de 29 de julio de 1837. Sobre los decretos, véase Revuelta, 2010: 361-396.

${ }^{3}$ Excavaciones realizadas en dos etapas (marzo-octubre y diciembre de 1984) demostraron la existencia de niveles de ocupación árabe y romanos en el emplazamiento donde se situaba el monasterio. Al respecto, véase CAMPOS, LORENZO, ESCUDERO Y AMORES, 1985: 361-365.

${ }^{4}$ El área del monasterio de San Agustín ocupaba en 1880 un total de 15.016 metros cuadrados: 7.391 correspondían al edificio y 7.625 a la huerta anexa (BARRAU, 1881: 26).

${ }^{5}$ Ortiz de ZúÑiga, 1988: 59. Esta cronología es defendida también por Llorden, 1944: 153. SÁnchez Pérez, 2001: 386.

${ }^{6}$ Arana de Varflora, 1789: 47.

${ }^{7}$ Los inicios del monasterio se vincularían a la compra, por Arias Yáñez, de unas casas extramuros de la Puerta de Carmona que eran propiedad de unas religiosas del Espíritu Santo dedicadas a adoctrinar niñas. Al respecto, véase MARtíneZ de Aguirre, 1992: 111.

${ }^{8}$ Para conocer las transformaciones sufridas por la Casa Grande de los agustinos hispalenses a lo largo de su historia, véase especialmente la reciente síntesis de FERNÁNDEZ RoJAS, 2008: 274-278.

Arch. esp. arte, LXXXVI, 344, octUBRE-DICIEMBRE 2013, 311-330, ISSN: 0004-0428 


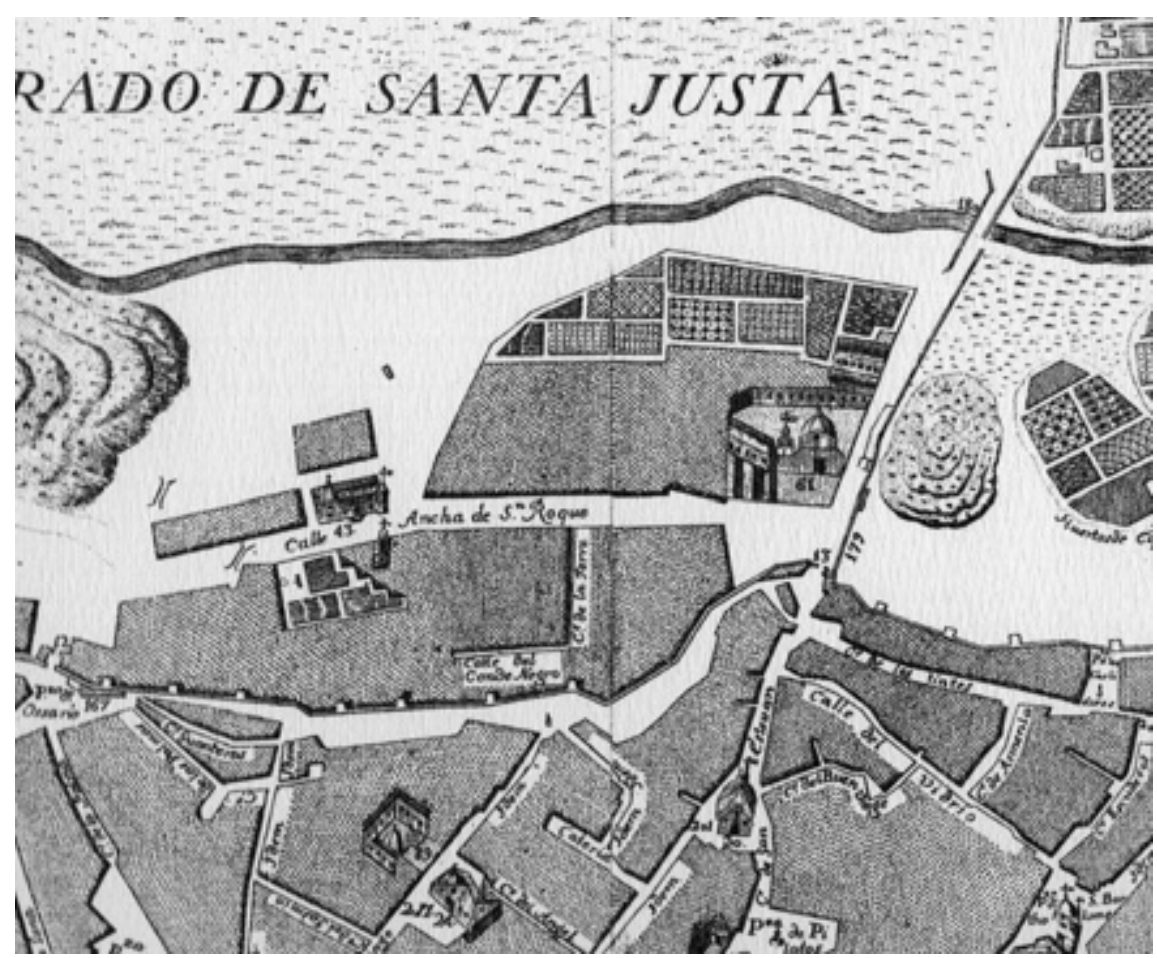

Fig. 2. Área urbana donde se asentaba el monasterio. F. Coelho y J. Amat. 1771. Archivo Histórico Municipal de Sevilla.

de 1810 supuso la expulsión de los religiosos agustinos, la conversión del cenobio en cuartel y el expolio y destrucción de gran parte de sus tesoros artísticos. Tras la liberación de la ciudad, dos años más tarde, el edificio continuó con usos militares y sirvió de sede al Real Cuerpo de Inválidos Inhábiles, que aún lo ocupaba en abril de $1814^{9}$. Ese año regresaron al convento los agustinos para abandonarlo definitivamente en 1835, a raíz de las leyes desamortizadoras ${ }^{10}$. Con la exclaustración, el monasterio fue reconvertido, desde 1837 , en presidio ${ }^{11}$, uno de los establecimientos mejor organizados de Sevilla ${ }^{12}$, donde los penados realizaban diferentes labores en talleres de carpintería, zapatería y espartería, entre otros ${ }^{13}$. Tras subastarse parte del edificio en

\footnotetext{
${ }^{9}$ Flores, 1817: 48-49.

${ }^{10}$ Sobre el progreso de la exclaustración, que quedará ligado íntimamente a la vida política del país, la guerra carlista y las luchas internas entre liberales moderados y progresistas, véase Revuelta, 2010.

${ }^{11}$ El 20 de mayo de 1837 la Diputación de Sevilla remite un oficio al Gobierno donde manifiesta la conveniencia de establecer en la ciudad un presidio para hombres, propuesta que es aceptada meses más tarde, el 9 de julio. El arquitecto municipal Melchor Cano inspecciona varios inmuebles de comunidades extinguidas, entre los que cabe destacar la Cartuja y los conventos de San Antonio y de los Capuchinos, pero finalmente, en contra de la opinión del arquitecto, se decide instalar el presidio en el cenobio agustino. Presidio peninsular, Archivo Histórico Municipal, Sevilla (AHM), Colección Alfabética, Caja 885, exp. 329, s. fol.

12 "Era digno de verse por su gran orden, policía, admirable limpieza y la elegancia de adornos e iluminación nocturna" (GONZÁLEZ DE LEÓN, 1973: 531).

${ }_{13} \mathrm{Tal}$ como pone de manifiesto un informe elaborado en julio de 1841 por la comisión municipal encargada de inspeccionar el estado del penal (Presidio peninsular, AHM, Colección Alfabética, Caja 885, exp. 329, s. fol.).
} 
agosto de 1880 , pues en ese momento ya no reunía las condiciones necesarias como penal, algunas de sus estancias desempeñaron otros cometidos y funcionaron como mercado, cuartel de intendencia y almacén de una empresa privada. Poco a poco, en sucesivas demoliciones que se iniciaron en los años ochenta del siglo XIX, con motivo de una operación urbanística que destruyó varias salas del convento para construir viviendas, y que llegaron hasta las primeras décadas del siglo XX, se perdió el magnífico conjunto arquitectónico que fue la Casa Grande de los agustinos hispalenses. Del histórico monasterio, con todo, se conservan todavía importantes estructuras como el espléndido refectorio gótico (figs. 3 y 4), algunos dormitorios, gran parte del claustro principal (fig. 5), la escalera por la que se accedía a los pisos altos o la portada renacentista de Hernán Ruiz II (fig. 6), restos de enorme relevancia que ya en 1964 fueron declarados Monumento Histórico-Artístico ${ }^{14}$.

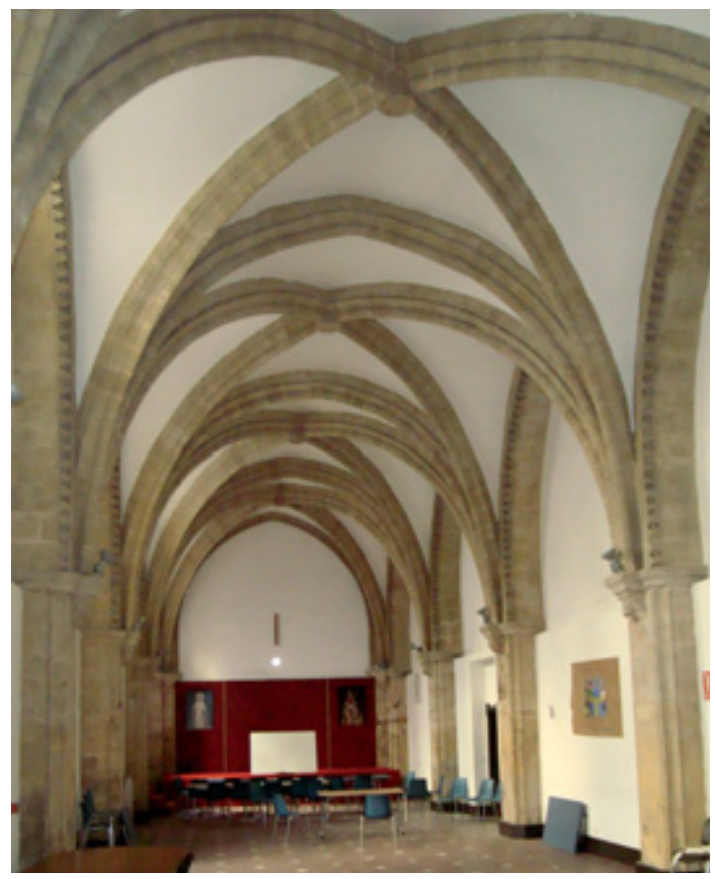

Fig. 3. Interior del refectorio de San Agustín. Siglo XIV.

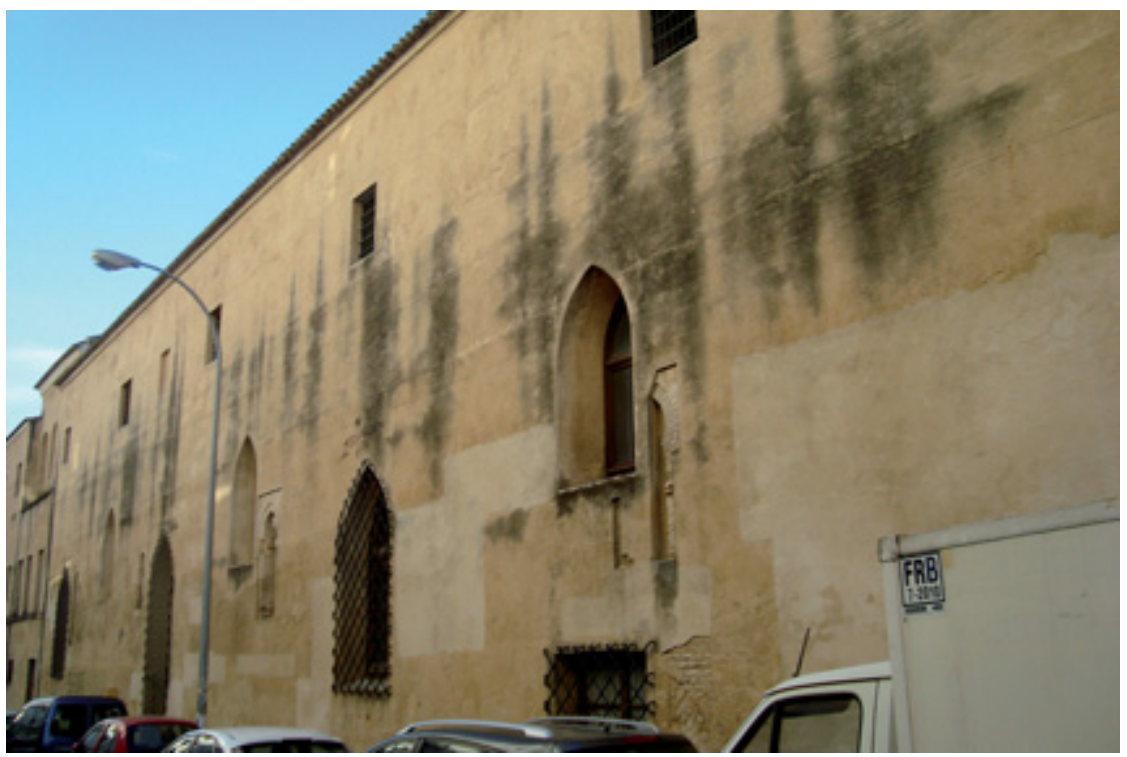

Fig. 4. Exterior del refectorio de San Agustín. Siglo XIV.

${ }^{14}$ La declaración fue ampliada el 2 de noviembre de 1990. Al respecto, véase Pérez CANO, 1996: 113. 


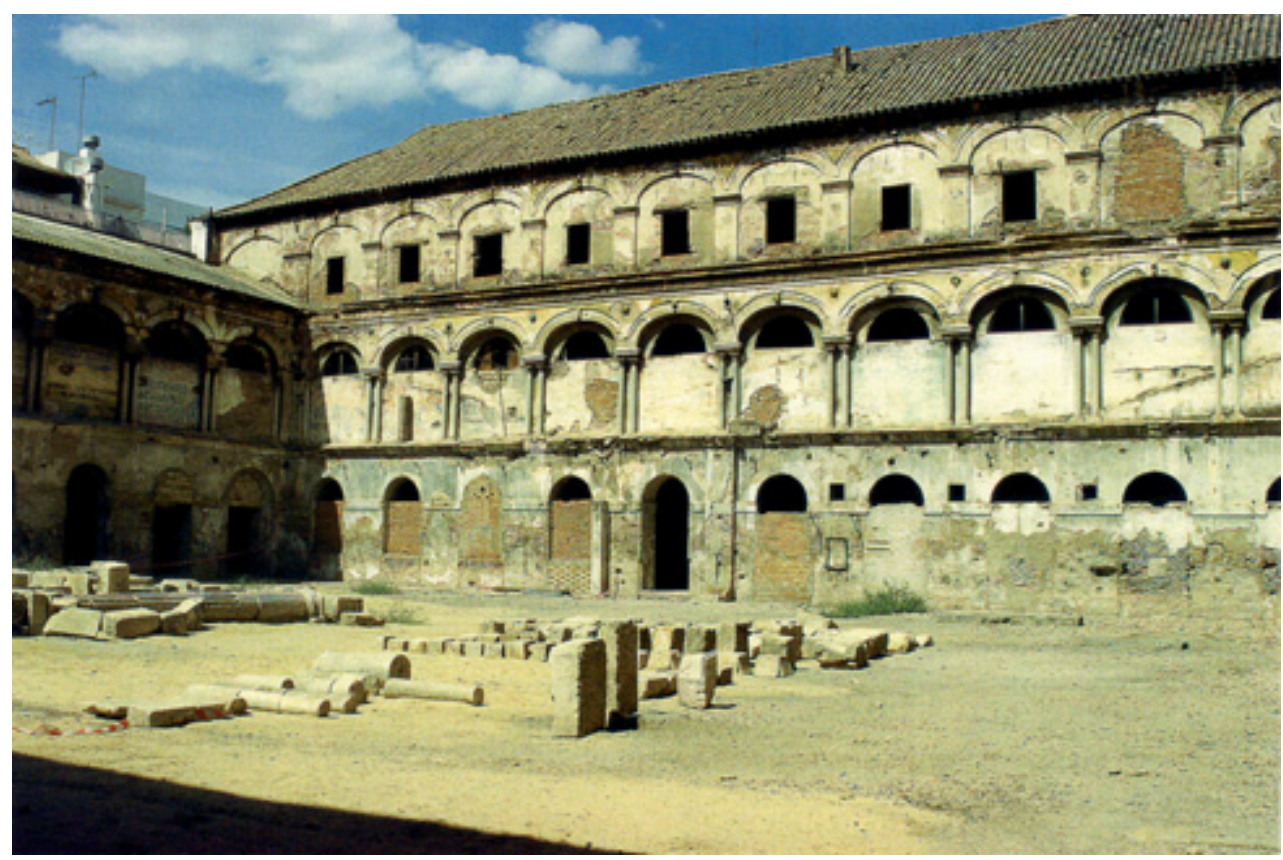

Fig. 5. Claustro principal del monasterio (Fotografía de E. Sánchez Pérez).

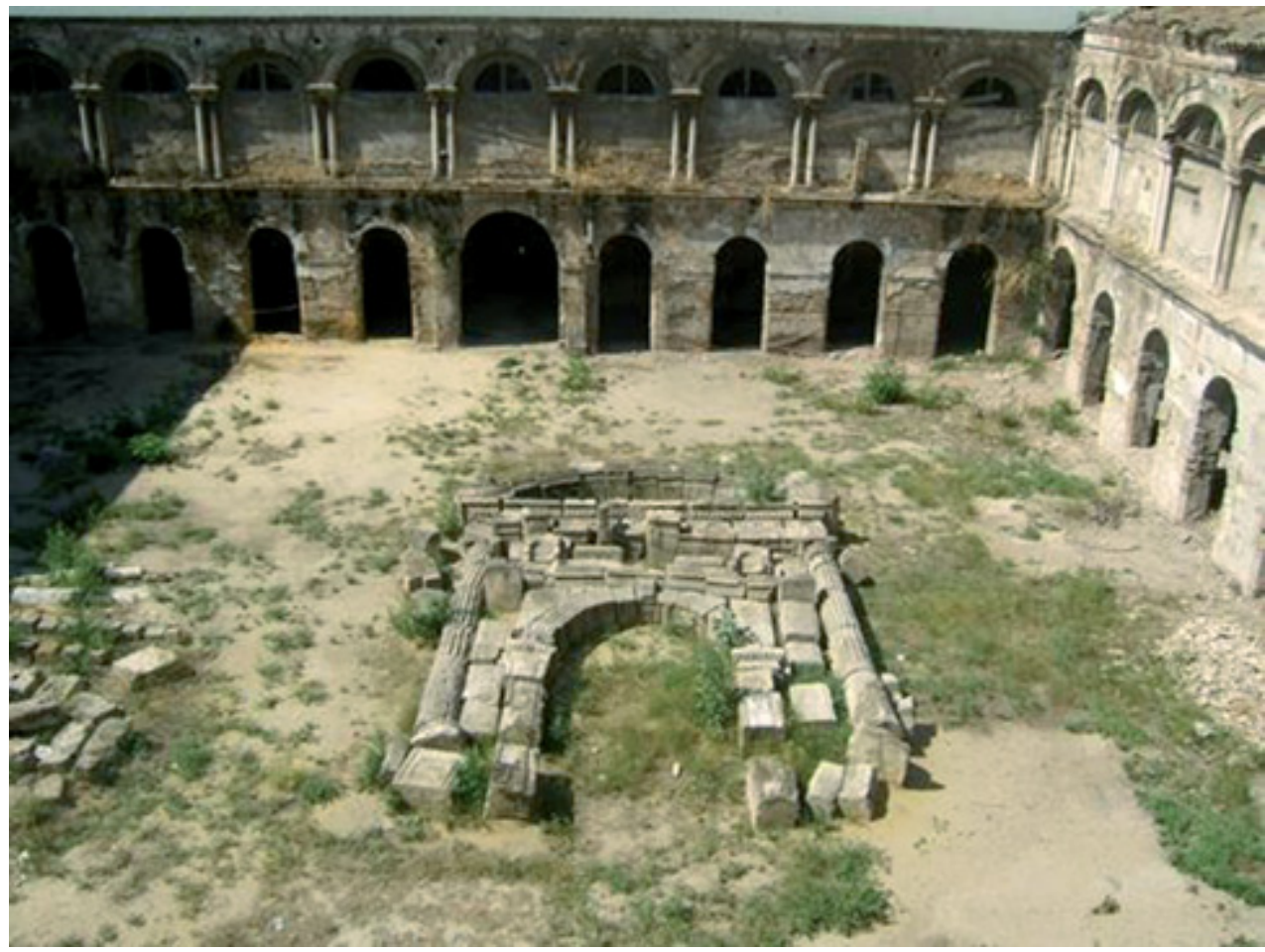

Fig. 6. Portada de Hernán Ruiz II. 1563.

Arch. esp. arte, LXXXVI, 344, octuBre-DICIEMBRE 2013, 311-330, ISSN: 0004-0428 


\section{Sobre la arquitectura y la distribución del edificio: fuentes y estudios}

La inexistencia de fuentes documentales originales ha sido siempre el mayor problema al que se han tenido que enfrentar los autores que han estudiado el monasterio sevillano de San Agustín. Esta carencia se debe a la destrucción sistemática de los documentos antiguos por parte de los claustrales, "cruel venganza, por no querer sujetarse a la Observancia", tal como refiere el anónimo autor del manuscrito escrito en 1700 que custodia el Archivo Histórico Municipal de Sevilla ${ }^{15}$.

Se conservan, no obstante, tres fuentes impresas del siglo XIX que aportan información sobre algunas estancias singulares del edificio. La más lejana en el tiempo es Antigüedades del convento Casa Grande de San Agustín, escrita por José María Montero de Espinosa en $1817^{16}$. El autor transcribe inscripciones hoy perdidas y hace referencia a las fiestas solemnes celebradas en el monasterio, en especial las relacionadas con el Santo Crucifijo, su imagen y su capilla. A pesar de que detalla sobre todo las numerosas obras de arte que atesoraban, tiene particular interés la descripción que hace Montero de las capillas de los claustros y de la iglesia. De la arquitectura de los claustros poco dice, salvo que son "dos grandes patios rodeados de columnas a que corresponden arcos en el segundo piso"17. Félix González de León, que es el autor de la segunda fuente de referencia, trató del monasterio en su conocida Noticia artística ${ }^{18}$. El texto, publicado en 1844, aporta mucha información sobre el patrimonio mueble perdido y el que todavía conservaba el exconvento. En relación con la arquitectura y la distribución del monasterio, González es algo más preciso que su antecesor y localiza mejor las estancias, dirigiendo su interés, eso sí, a las piezas descritas por Montero. Se refiere al claustro principal y a sus correspondientes capillas; a la iglesia en general, de la que aporta datos estructurales; y a las diferentes capillas que poseía el templo. Incluye más información que Montero de Espinosa sobre el claustro de los novicios, que define como "no tan grande como el primero; pero de arcos sobre columnas, bajos y altos, y de bastante extensión"; y menciona, además, "otros patios menores", sin describirlos ni localizarlos. De la sala de profundis y el refectorio dice simplemente que "eran piezas magníficas y dilatadas", mostrando más atención por la monumental y espléndidamente decorada escalera de acceso al piso alto, que sitúa en el claustro principal ${ }^{19}$. Notas históricas acerca el ex-convento de San Agustín, publicada en 1881 por el ingeniero Leoncio Barrau ${ }^{20}$, es la tercera fuente impresa. Con la intención de reformar el edificio e instalar un moderno mercado de abasto en su patio principal, Barrau y sus socios José Caso e Isaías White compraron, en 1880, una parte del viejo caserón al Estado, pues el sector oriental del histórico conjunto arquitectónico, que comprendía el claustro de los novicios y las dependencias adyacentes, se remodeló como intendencia militar, y la parte norte del viejo cenobio estaba arruinada. Por su condición de ingeniero, supongo, Leoncio Barrau se encargó de habilitar la propiedad; y después de diez meses de trabajo, como explica en las páginas introductorias de su texto, decidió "conocer la historia" del edificio y describirlo. Nada nuevo aporta sobre la dilatada historia del monasterio, pues repite los datos proporcionados por Ortiz de Zúñiga y otros autores; pero es mucho más riguroso que Montero y González a la hora de recoger las dimensiones de las estancias que todavía permanecían en pie. Al identificar la antesacristía y la capilla de Esquivel, y seguramente al localizar la sala de profundis, comete, sin embargo, algunos errores. Concluye Barrau su descripción con una breve referencia a las obras que se estaban realizando en el sector oriental y

${ }^{15}$ Para la historia del convento de N. P. S. Agustín de Sevilla, AHM, Sección 11, Tomo XV, doc. 12. Este documento lo dio a conocer Martínez de AguirRe, 1992: 110.

${ }^{16}$ Montero de Espinosa, 1817.

${ }^{17}$ Montero de Espinosa, 1817: 46-47.

${ }^{18}$ GonZÁlez de LeÓN, 1973: 518-531.

19 GonZÁlez de LeÓN, 1973: 530.

${ }^{20}$ Barrau, 1881.

Arch. esp. arte, LXXXVI, 344, octUBRE-DICIEMBRE 2013, 311-330, ISSN: 0004-0428 
una alusión a las salas situadas en el lado norte, "afectas a cocinas, panadería y dependencias del servicio", piezas que habían sido demolidas ${ }^{21}$.

Montero de Espinosa y González de León proporcionan amplios datos sobre los retablos, las esculturas y las pinturas del monasterio, y documentan también muchas construcciones, pero no aclaran la distribución de la clausura. Es más, aunque sus descripciones fueran más detalladas de lo que en realidad son, no podrían establecer tampoco la exacta compartimentación de la arquitectura, pues sólo un levantamiento planimétrico puede reflejarla. Ambos textos, no obstante, han resultado muy esclarecedores al cotejarlos con la planta de 1835. El libro de Montero es dieciocho años anterior al plano de León y Canales, y corresponde, por tanto, al momento en que la comunidad se estaba esforzando en restaurar los destrozos causados por las fuerzas francesas de ocupación. Sus descripciones me han permitido situar, con cierta aproximación, los antiguos espacios correspondientes a las capillas de Esquivel, de Nuestra Señora del Tránsito y de San Juan de Sahagún. La ubicación de la capilla de los Vargas, que se emplazaba según el referido autor entre los dos claustros, es mucho más problemática. Por desgracia, no he podido sacar partido a su valiosa información sobre las capillas de la iglesia conventual, ya que éstas no figuran delineadas en el plano del ingeniero militar, que se limitó a levantar y localizar el perímetro del templo, lo que constituye un avance porque no estaba gráficamente documentado. El texto de González de León es nueve años posterior a la planta trazada por León y Canales, así que muchos espacios de la histórica clausura ya se habían adaptado al nuevo destino del edificio como presidio correccional. Los escuetos datos que proporciona sobre la antesacristía y la escalera monumental, con todo, me han resultado muy útiles para corroborar sus respectivas ubicaciones en la planta de 1835. Los cuarenta y seis años transcurridos entre el levantamiento planimétrico del ingeniero militar y el escrito de Leoncio Barrau aconsejan cierta precaución, pero el texto de 1881 confirma, una vez más, en líneas generales, la descripción de Montero de Espinosa. El plano hallado verifica la breve alusión de Barrau sobre el sector norte del edificio, el más desconocido del conjunto arquitectónico, pero además de las referidas piezas de servicio, se constatan varios dormitorios, un pequeño patio y dos jardines, estancias que al igual que las dispuestas en la parte este del complejo, alrededor del claustro de los novicios, tampoco se conocían.

De las fuentes gráficas sobre el monasterio que se conservan, todas ellas genéricas y poco precisas, es especialmente significativo el dibujo realizado por Richard Ford en 1831 (fig. 7). A la izquierda de la panorámica, se distingue la muralla medieval; justo en el centro aparece representada la Puerta de Carmona; y ocupando el sector derecho de la imagen se constatan perfectamente los Caños de Carmona y el flanco sur de la Casa Grande de San Agustín, cegado en parte por el histórico acueducto, del que se aprecian varios tramos bien diferenciados. El dibujo del famoso viajero y escritor británico reproduce el muro meridional del compás y su cubierta, la iglesia conventual y una de sus torres, o tal vez las dos, así como varias estructuras de difícil identificación que podrían corresponder, quizá, a la sacristía y a una capilla. La vista, desde luego, es ambigua, y he tenido que compararla con la planta de 1835 para opinar sobre ella con ciertas garantías.

Las excavaciones arqueológicas realizadas en dos etapas a lo largo de 1984, primero por el Museo Arqueológico, y luego por la Delegación de Cultura, fueron motivadas por un proyecto de edificación para los diferentes solares que quedaban libres dentro del conjunto arquitectónico. Tenían un triple objetivo: localizar posibles restos de la necrópolis romana asentada en las proximidades; comprobar la exactitud de un antiguo plano del convento de fecha desconocida (se trata de una planta, tal vez de finales del siglo XIX o incluso del XX, que describe el claustro principal y las dependencias adyacentes), fuente gráfica que ni está documentada ni se reproduce

\footnotetext{
${ }^{21}$ BARRAU, 1881: 27-35.
} 


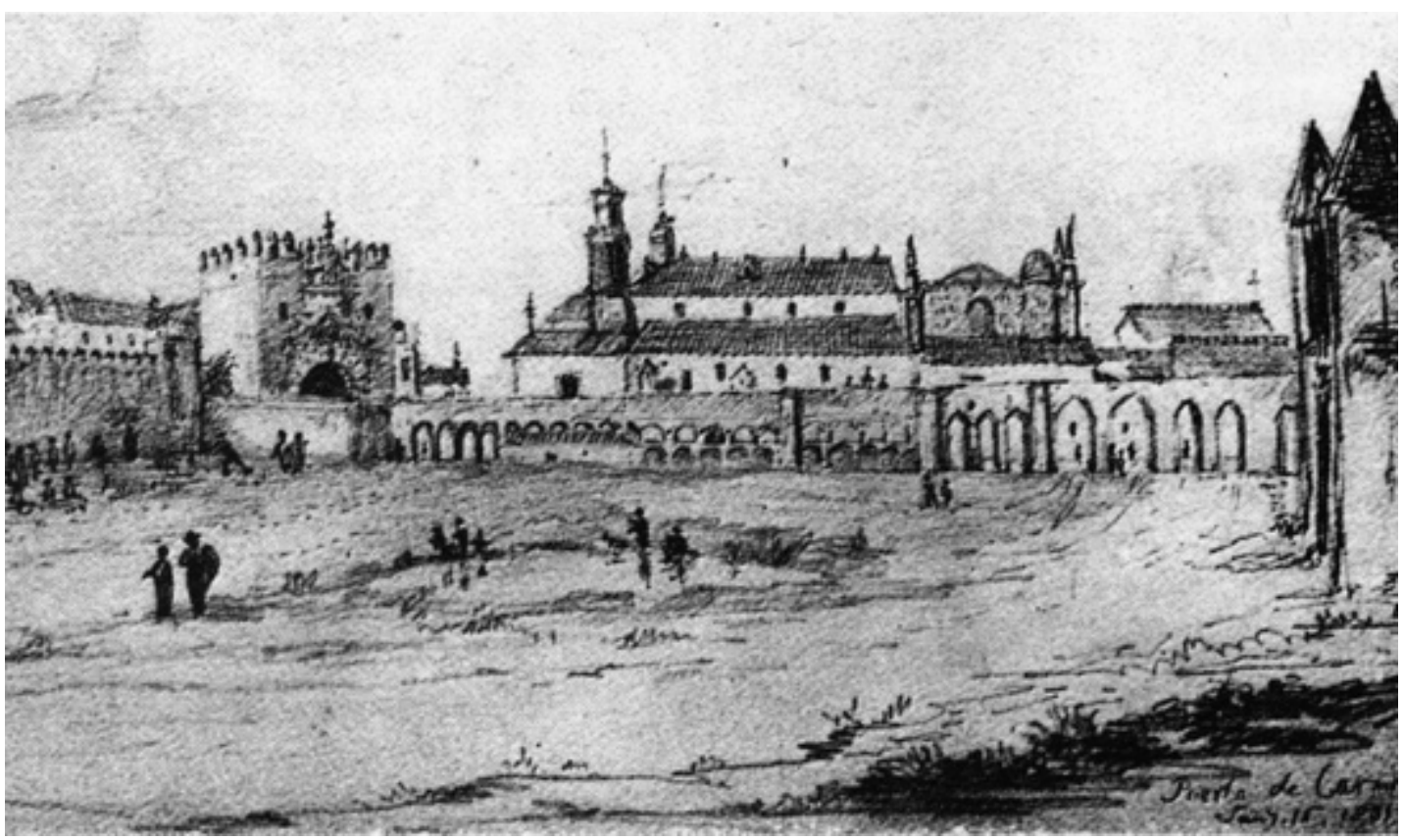

Fig. 7. Vista exterior de la Puerta de Carmona, acueducto y monasterio de San Agustín. R. Ford. 1831.

fielmente, pues se ha utilizado como un simple referente de las actuaciones arqueológicas ${ }^{22}$; y documentar la planta de la iglesia. Tras la intervención arqueológica, se descubrió una de las necrópolis romanas que rodeaban la ciudad, se hallaron los restos de una construcción mudéjar edificada a la vez que el refectorio, y se constató la estructura del claustro de los novicios, cuyos restos han quedado integrados en las nuevas viviendas ${ }^{23}$. El espacio donde siglos atrás se emplazaba la casa mudéjar lo he podido localizar en la planta de 1835 sin demasiados problemas, pero las dimensiones excavadas del claustro de los novicios no se ajustan a lo levantado por León y Canales ${ }^{24}$.

Aunque no describen la Casa Grande de los agustinos hispalenses, deben destacarse dos estudios que analizan dos importantes estructuras del viejo monasterio que todavía se conservan. Una de ellas, que necesita, desde luego, una rápida y decidida recuperación y reubicación, es la monumental portada de cantería que daba acceso al compás de entrada a la clausura (fig. 6). A esta obra de Hernán Ruiz II, Alfredo Morales dedicó, en 1985, un instructivo trabajo ${ }^{25}$. Morales, en su artículo, da a conocer una valiosa fotografía realizada en 1931 por Antonio Sancho Corbacho (fig. 8) que se conserva en la hoy Fototeca del Laboratorio de Arte, archivo gráfico vinculado al Departamento de Historia del Arte de la Universidad de Sevilla; documenta la autoría de la obra y analiza el estilo y el esquema compositivo de la portada, que se relaciona con otras obras del artista rea-

${ }^{22}$ Este plano antiguo del convento con las actuaciones arqueológicas y los cortes excavados lo han publicado CAMPOS, Lorenzo, Escudero y Amores, 1985: 363. No lo he podido incluir en este trabajo porque no se cita la procedencia ni se reproduce tal como se conserva.

${ }^{23}$ Campos, Lorenzo, Escudero y Amores, 1985: 364. También Murillo Díaz y Campos Carrasco, 1986: 703-716.

${ }^{24}$ Esta cuestión se trata en detalle más adelante, en el apartado dedicado al análisis de la planta de 1835.

${ }^{25}$ Morales, 1985: 173-182. 


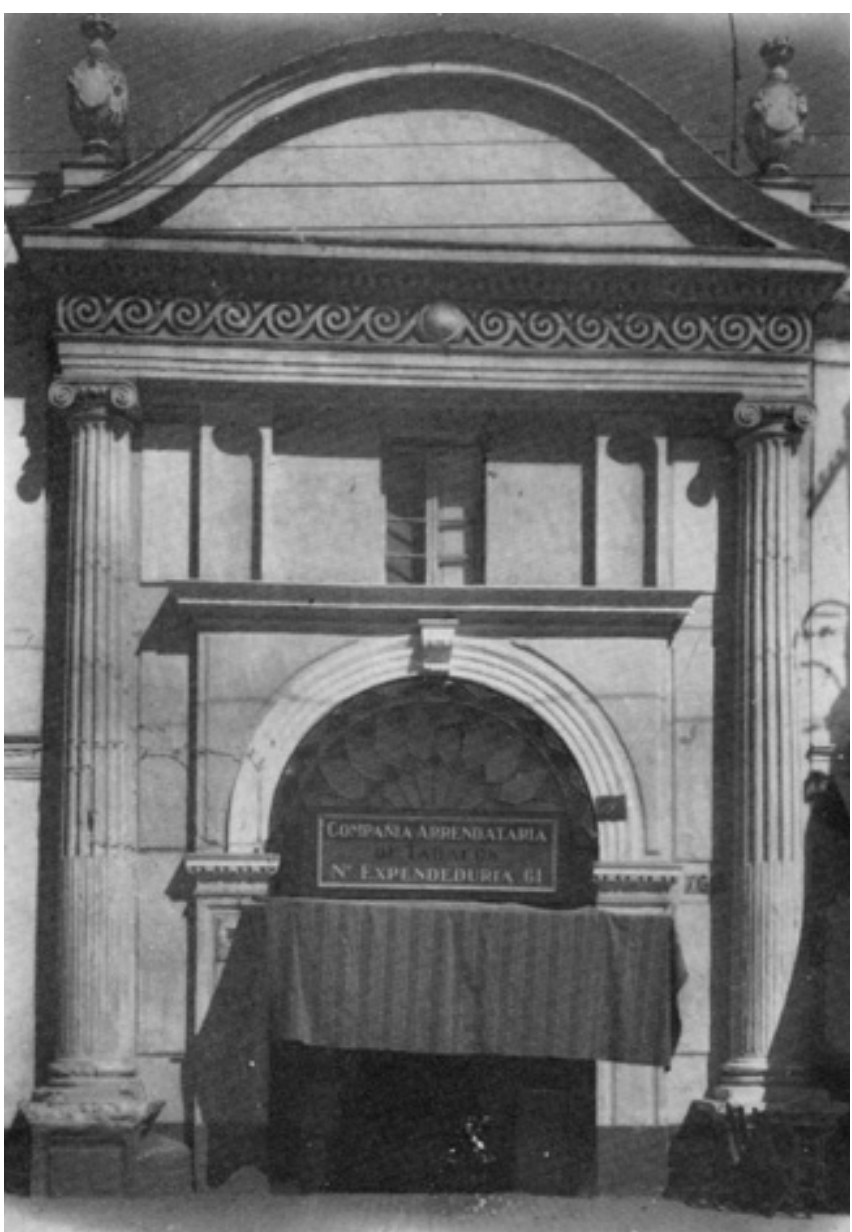

Fig. 8. Portada de Hernán Ruiz II. Fotografía de A. Sancho Corbacho. 1931 (Fototeca del Laboratorio de Arte). lizadas en Sevilla y otras localidades y con algunos dibujos del Manuscrito de Arquitectura. La otra estructura que se conserva, y en buen estado, por fortuna, es el refectorio del convento (figs. 3 y 4). Fue Diego Angulo Íñiguez ${ }^{26}$, en 1932, citando el "trabajo inédito que el señor Jiménez Placer había presentado a la clase de Historia del Arte del doctorado en Filosofía y Letras", quien rescató esta importante dependencia bajomedieval para la Historia del Arte. El análisis de esta obra clave para entender la asimilación del lenguaje gótico en Sevilla, no obstante, lo llevó a cabo varias décadas más tarde, en 1992, para ser exactos, Javier Martínez de Aguirre ${ }^{27}$. En su pormenorizado estudio del refectorio, Martínez valora aspectos estilísticos y ornamentales, que le han permitido fechar la obra después del segundo tercio del siglo XIV, así como el sistema constructivo.

Muy recientemente, Matilde Fernández Rojas ${ }^{28}$, en su libro sobre el patrimonio artístico de los conventos masculinos desamortizados en Sevilla, ha dedicado un amplio y bien documentado capítulo a la arquitectura, escultura y pintura del monasterio que constituye una acertada síntesis de toda la bibliografía.

\section{El ingeniero militar Benito León y Canales}

Poco se puede precisar sobre el autor del plano localizado en el Archivo General Militar de Madrid. Se sabe que Benito León y Canales ingresó en el Cuerpo de Ingenieros en 1813, que recibió dos cruces de San Fernando de primera clase por sus méritos y que su último destino fue en Granada, en la Dirección-Subinspección de Andalucía ${ }^{29}$.

El trazado de los planos y mapas necesarios para la construcción de fortificaciones o de otras obras de carácter militar o civil ha sido siempre una tarea propia de los ingenieros militares. De

\footnotetext{
26 Angulo ÍÑIGUeZ, 1932: 18-19.

${ }^{27}$ Martínez de Aguirre, 1992: 109-131.

${ }^{28}$ FernándeZ Rojas, 2008: 273-295.

${ }^{29}$ Carrillo de Albornoz, 2001: 158.
} 
hecho, en la Teoría y Práctica de Fortificación de Cristóbal de Rojas, texto publicado en Madrid en 1598, ya se explica el procedimiento adecuado para realizar levantamientos topográficos ${ }^{30}$. Las instrucciones van a ser mucho más técnicas y detalladas a partir de la creación del Cuerpo de Ingenieros en $1711^{31}$, destacando en este sentido la Ordenanza de 1803, que va a regular el método y el material topográfico de las brigadas ${ }^{32}$.

A los levantamientos que entre noviembre y diciembre de 1835 llevó a cabo Benito León y Canales en varios conventos hispalenses que se proyectaban transformar en cuarteles, documentos gráficos que adquieren una gran relevancia como fuentes para el estudio del patrimonio arquitectónico desaparecido en Sevilla, he dedicado recientes trabajos ${ }^{33}$. Del análisis de los dibujos del ingeniero se puede concluir que el sistema gráfico de representación utilizado es similar en todos los casos: para trazar las líneas arquitectónicas sobre el papel, que es el soporte empleado, se usa tinta roja, y para definir los espacios abiertos, colores a la aguada. En la planta correspondiente al monasterio de San Agustín (fig. 1), la variación de textura también se aprecia en el entorno urbano ("Casas del Barrio") y en la extensa huerta del convento. Con objeto de facilitar la identificación de las piezas que componen la clausura, se emplea un sistema alfanumérico que es explicado en un pequeño abecedario que figura a la izquierda del documento gráfico. Pero además de letras y números, se incluyen anotaciones complementarias que señalan las calles ("[Calzada de los] Caños de Carmona") y aclaran todavía más la exacta distribución del edificio ("Porche", "Patio", "Yglesia", "Sacristía"). Se registra la fecha de realización, el nombre del convento representado, el autor del plano y el visto bueno de Sierra, un técnico militar de rango superior. Lleva también escala en varas.

\section{La planta del monasterio sevillano de San Agustín}

La planta de 1835 (fig. 1) constata numerosas estancias que prueban el carácter monumental que tradicionalmente se ha atribuido al edificio agustino. En el sector izquierdo de la planta de Benito León y Canales, que corresponde al frente septentrional del monasterio, se distingue claramente un gran espacio cultivado ("Huerta") y algunos inmuebles de particulares ("Casas del Barrio"), que por su proximidad respecto al convento y su concreto emplazamiento se podrían relacionar tal vez con antiguas posesiones de la Orden. Justo al lado de las viviendas figura en el plano un pequeño jardín cercado $\left(\mathrm{n}^{\circ} 12\right)$ que se ubica entre un espacio cuadrangular de servicio $\left(\mathrm{n}^{\circ} 13\right)$ destinado a los caballos ("Cuadras") y la denominada "Habitación del Procurador" (n $\left.\mathrm{n}^{\mathrm{o}} 11\right)$. Otro jardín de recreo $\left(\mathrm{n}^{\mathrm{o}} 12\right)$, también cerrado, pero mucho más extenso que el anterior, se localiza a la altura de la huerta de los monjes. Hacia el este, contiguo al huerto de los monjes, aparece delineada una estancia rectangular que era utilizada en ese momento como almacén $\left(n^{\circ} 5\right)$.

La compartimentación del frente occidental de la Casa Grande, es decir, la correspondiente a la fachada principal del monasterio, se detalla en la sección inferior del documento gráfico. Anexas a las ya mencionadas "Casas del Barrio", se disponen algunas dependencias en torno a un pequeño claustro ("Patio"), probablemente de servicio, que comunica a su vez con la aludida "Habitación del Procurador" ( $\left.\mathrm{n}^{\circ} 11\right)$, un almacén $\left(\mathrm{n}^{\circ} 1\right)$, varias estancias sin identificar y un espacio con salida a la calle ancha de San Roque, hoy de Recaredo, que se describe como "Puerta del Campo" ( $\left.\mathrm{n}^{\circ} 14\right)$ y que posiblemente, dada su ubicación, sería el acceso por donde entraban los carros, siendo, por

${ }^{30}$ RoJAs, 1598: $2^{\mathrm{a}}$ parte, cap. XXIII.

${ }^{31}$ Sobre su historia, la estructura institucional y la formación científica que recibían los ingenieros, véase CAPEL, SÁNCHEZ y MONCADA, 1988.

32 Quesada Gómez, 1997: 372-373.

33 Fernández GonZÁlez, 2012: 155-166. Fernández GonZÁlez y Varas Rivero, 2012. 
tanto, la principal entrada de servicio. A continuación se distinguen una serie de dependencias $\left(\mathrm{n}^{\circ} 2, \mathrm{n}^{\circ} 3 \mathrm{y} \mathrm{n}^{\circ} 4\right)$ que en 1835 eran utilizadas también como "Almacenes". La más meridional $\left(n^{\circ} 4\right)$ es la de mayor tamaño, tal como documenta la planta del ingeniero militar, pues alberga varios espacios compartimentados que corresponden, a mi entender, a los solares excavados en la campaña arqueológica de 1984, donde se hallaron las estructuras de un patio con habitaciones y galerías anexas que habían sido construidas aprovechando y remozando una edificación anterior mudéjar que debió de realizarse a la vez que el refectorio ${ }^{34}$. Se aprecia también una puerta de comunicación directa con la calle y un acceso a los pisos altos que seguramente, por su posición en el ángulo noroeste del claustro, corresponde a la escalera que llevaba a las galerías claustrales, a las celdas de la primera planta y a la biblioteca ${ }^{35}$. Pienso que la regular estancia sin referencia alguna que figura contigua en el levantamiento de León y Canales se podría relacionar, a partir de la descripción de Montero de Espinosa ${ }^{36}$, con el espacio que ocupaba la antigua capilla de Nuestra Señora del Tránsito, y que en el pequeño ámbito que viene a continuación (letra B), situado entre la referida capilla y el compás ("Porche") de acceso al convento y la iglesia, estaría emplazada la capilla de Sahagún. Ambas estancias, por supuesto, sufrieron varias remodelaciones desde el último tercio del siglo XVII que alteraron su estructura original. En unas salas desocupadas de la planta alta que daban al corredor oeste del claustro principal y al entonces denominado "camino y calle real", hoy calle de Recaredo y plaza de San Agustín, y que se extendían por encima de la portería (letra B) y de la pieza contigua a ella hasta la escalera antes referida que en el plano de 1835 ocupa gran parte del muro sur de la dependencia señalada con el $\mathrm{n}^{\circ} 4$, siglos atrás, en agosto de 1567 , se había previsto edificar una hospedería para los frailes de la orden agustina que desde Sevilla emprendían viaje a las colonias americanas o bien regresaban de ellas. La planta del maestro albañil Benito de Morales, con las dimensiones y la distribución proyectada para la obra, todavía se conserva en el Archivo General de Indias ${ }^{37}$ (fig. 9). Morales y el maestro carpintero Juan Pérez, "que son de los más prácticos y de más experiencia que hay en la ciudad", según consta en los documentos, tras inspeccionar el convento y verificar que los monjes agustinos "no tienen para hospedería más que una pieza baja, pequeña", planeaban construir dieciocho dormitorios y tres piezas bajas donde se almacenaría el equipaje de los viajeros, intervención que fue presupuestada por ambos maestros en 6.000 ducados $^{38}$.

Frente a la muralla y la Puerta de Carmona, ocupando el ángulo suroccidental del complejo monacal, aparece dibujada la entrada principal del edificio ${ }^{39}$ (letra A). Ahí precisamente se ubicaba la monumental portada de Hernán Ruiz II ${ }^{40}$, obra que a finales del setecientos, por su "regularidad", había cautivado al ilustrado viajero Antonio Ponz ${ }^{41}$. En 1931, como se ha explicado, fue fotografiada por Sancho Corbacho en su emplazamiento original (fig. 8). Desmontada en los años cincuenta del siglo XX, hoy se encuentra despiezada en el suelo del claustro principal (fig. 6). Esta

34 Al respecto, véase Murillo Díaz y Campos Carrasco, 1986: 703-716.

${ }^{35}$ Tanto el amplio salón abovedado de la biblioteca como el resto de las dependencias que lindaban con la calle de Recaredo estaban en buen estado en 1880. Incluso la monumental escalera conservaba en ese momento referencias cronológicas a las intervenciones de 1575 y 1585, así como su alicatado y artesonado (BARRAU, 1881: 20, 27). Sobre la valiosa colección de libros de albergaba la biblioteca, que se perdió con la invasión francesa, véase MonTERO DE ESPINOSA, 1817: 112-140

${ }^{36}$ Montero de EspinosA, 1817: 44-45.

${ }^{37}$ Planta para la hospedería del convento de San Agustín de Sevilla, Archivo General de Indias, Sevilla (AGI), Mapas Planos, Europa-África, $n^{\circ} 74$.

${ }^{38}$ AGI. Indiferente general, 2005, s. fol

${ }^{39}$ En el plano de Benito León y Canales (fig. 1), en el abecedario que figura a la izquierda del documento gráfico, se lee: "A. Entrada principal distante unas 40 varas de las murallas"

${ }^{40} \mathrm{Al}$ respecto, véase Morales, 1985: 173-180.

${ }^{41}$ Ponz, 1972: 135. 


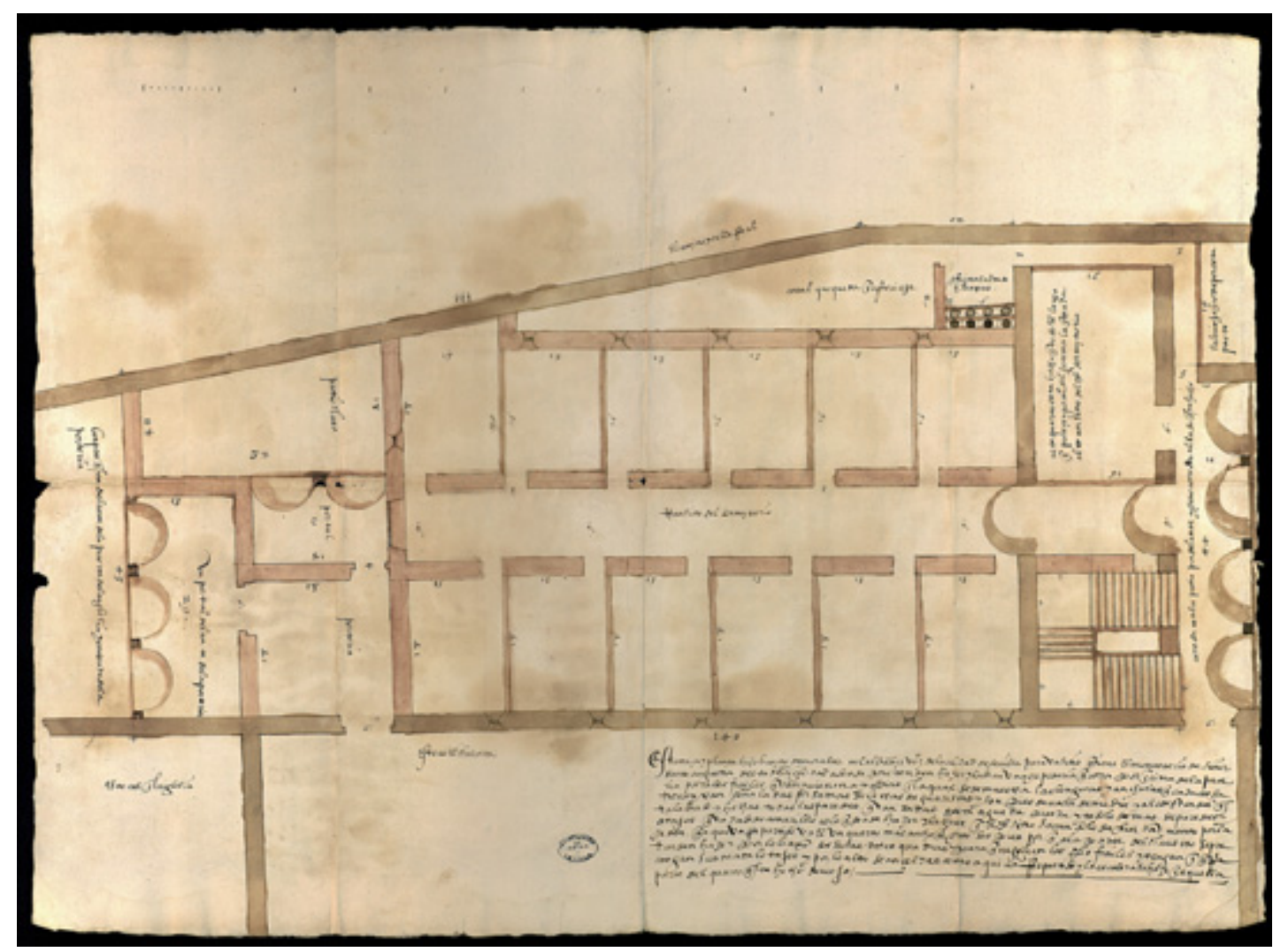

Fig. 9. Planta para la hospedería del monasterio San Agustín. B. de Morales. 1567. Archivo General de Indias.

portada renacentista daba acceso al compás ("Porche"), estancia que comunica con el templo conventual ("Yglesia") y con el estrecho "Pórtico" (letra B), antes referido, que conducía a la clausura y que evidencia una doble arcada de entrada. Aunque el levantamiento de León y Canales no la recoge, la plaza de San Agustín se sitúa justo enfrente de la portada principal del monasterio, tal como detalla el plano de 1771 que mandó realizar el asistente Olavide (fig. 2). Este sector de Sevilla, en 1835, había perdido protagonismo urbano, pero décadas más tarde, en el último tercio del ochocientos, una vez derribadas las murallas y la Puerta de Carmona y después de sufrir sucesivas ordenaciones, dejará de ser periférico ${ }^{42}$. El proyecto de alineación de la plaza, que conformará finalmente un ámbito circunscrito a un pequeño espacio triangular abierto a la calle de Recaredo y a la plazoleta de la Concepción ${ }^{43}$, fue trazado por el arquitecto municipal Francisco Aurelio Álvarez Millán en diciembre de 1878 (fig. 10) y aprobado por el Consistorio hispalense el 7 de febrero de $1879^{44}$. El proyectismo municipal para este sector de la ciudad no estaba presidido exclusivamente por el criterio decimonónico de alineación y ensanche, también tomaba en consideración

\footnotetext{
42 SuÁrez Garmendia, 1986: 263-270, 279-284.

43 Collantes, Cruz, Reyes y Rodríguez, 1993: 292-294.

${ }^{44}$ AHM, Colección Alfabética, Alineaciones, Caja 32, exp. 24.571, s. fol.
} 


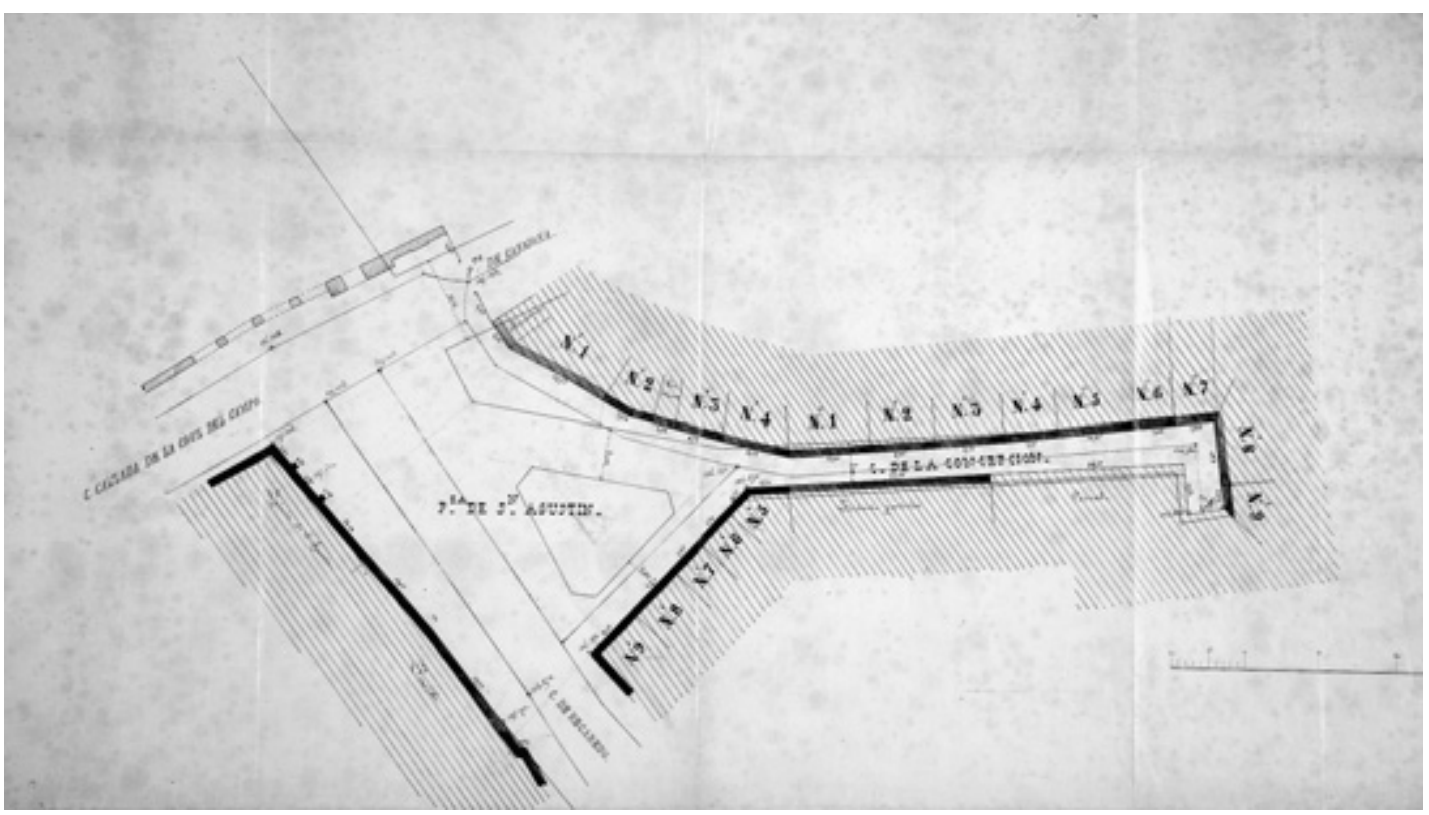

Fig. 10. Proyecto para la plaza de San Agustín. F. A. Álvarez Millán. 1878. Archivo Histórico Municipal de Sevilla.

el embellecimiento urbano, como demuestra el plan de intervención pergeñado el 21 de octubre de 1887 por el ingeniero titular del Ayuntamiento Ángel Romero, proyecto que pretendía instalar una fuente y un pequeño paseo arbolado en la plaza de San Agustín ${ }^{45}$.

Se sabe que la iglesia del monasterio tenía tres naves y era muy espaciosa porque contaba con numerosas capillas; en origen debió de combinar elementos góticos con mudéjares, pero la fábrica, muy alterada por la intensa actividad constructiva de los siglos XVI y XVII ${ }^{46}$, en 1835, cuando el ingeniero militar llevó a cabo el levantamiento, era ecléctica, como es evidente. Un año más tarde fue saqueada y destruida por las milicias de voluntarios de Andalucía que se acantonaron en el convento para hacer frente a las tropas carlistas ${ }^{47}$. Aunque la planta de Benito León y Canales señala la ubicación exacta del templo ("Yglesia"), no detalla, por desgracia, su distribución interior y no se puede verificar, por tanto, si las capillas de patronazgo conformaban estructuras arquitectónicas independientes o eran sencillos altares, con sus correspondientes sepulcros, situados a lo largo de las naves. Contigua al ábside del templo, se distingue una dependencia $\left(\mathrm{n}^{\mathrm{o}} 14\right)$ que en ese momento enmascaraba externamente la cabecera de la iglesia, pues la estancia abarca toda su extensión. Esta pieza tenía salida al exterior ("Puerta del Campo") y comunicaba con la antesacristía $\left(n^{\circ} 6\right)$ mediante un corredor que enlazaba ambos accesos y terminaba en una escalera de subida al piso alto. El muro sur del templo conventual, que define en gran medida el flanco meridional de la Casa Grande agustina, se orientaba hacia la antigua vía Augusta romana que más tarde, por el acueducto que corría en paralelo al camino de acceso a la ciudad, recibiría los nombres de Cal-

\footnotetext{
${ }^{45}$ AHM, Colección Alfabética, Paseos, Caja 539, exp. 32, s. fol., y Caja 540, exp. 267, s. fol.

${ }^{46}$ Montero de Espinosa, 1817: 10, 23-36, 49. GonzÁlez de León, 1973: 518-524. Barrau, 1881: 34-35.

47 GonZÁlez de LeÓN, 1973: 527.
} 
zada de los Caños de Carmona, como anota León y Canales en el plano; Calzada de la Cruz del Campo, por conducir al humilladero de este nombre; calle Oriente, en 1869; y Luis Montoto, en la actualidad.

El claustro principal ("Patio") del monasterio (fig. 5) se localiza en la planta de 1835 paredaño al muro de la iglesia que corresponde al lado del evangelio, sector hoy ocupado por construcciones modernas. El levantamiento describe su planta cuadrada y sus cuatro corredores abovedados ${ }^{48}$ (letra C), que estaban decorados, como es conocido, con pinturas de gran formato alusivas a la vida del santo titular del monasterio ${ }^{49}$, pero no reproduce la fuente que centralizaba el patio. Décadas más tarde, el 25 de mayo de 1881, concretamente, José Caso Aldana, Isaías White y el ingeniero Leoncio Barrau Galinier, como nuevos propietarios de una parte del viejo edificio de los agustinos ${ }^{50}$, presentan al Ayuntamiento hispalense un proyecto, bajo planos de Rafael López, para instalar en el claustro principal y sus cuatro galerías cubiertas un moderno mercado de abasto. Tanto el proyecto (fig. 11) como las condiciones facultativas de la obra, que también fueron establecidas por López, se custodian en el Archivo Histórico Municipal de Sevilla y hasta ahora no se habían publicado ${ }^{51}$. El plan de los inversores, además del establecimiento del mercado, contemplaba una lucrativa operación urbanística que valoraba ya el futuro ensanche de la ciudad hacia Santa Justa, pues Caso, White y Barrau proyectaban fraccionar la gran manzana donde se asentaba el histórico monasterio mediante la apertura de dos calles que al cruzarse en ángulo recto en el interior de la finca permitirían la parcelación del suelo en solares ${ }^{52}$. Aunque la entrada principal al establecimiento comercial sería por la plaza de San Agustín, se había previsto un acceso peatonal por la calle de Oriente que atravesaría el solar de la ya demolida iglesia conventual ${ }^{53}$. Más adelante, para completar la intervención y facilitar la entrada a la plaza de abastos por sus cuatro ángulos, se abriría la otra vía de comunicación propuesta. Esta calle, que discurre paralela al costado norte del refectorio (fig. 11) y atraviesa de este a oeste el viejo edificio agustino, se distingue perfectamente en el plano de Sevilla delineado por Antonio de Padura y Manuel de la Vega Campuzano en 1891 (fig. 12). No es otra, por tanto, que la antigua calle de fray Alonso, hoy de San Alonso de Orozco (fig. 4), que recuerda al obispo agustino promotor de la construcción del refectorio en 1366. Al contrario de lo que se creía, la calle no fue trazada en realidad sobre la antigua huerta del convento, sino más bien sobre las distintas estancias que aparecen dibujadas en el levantamiento de $1835^{54}$ (figs. 1, 11 y 12). Para acceder al mercado, según establece el proyecto de Rafael López, se tenía que atravesar "un extenso salón con artesonado antiguo" que iba a funcionar como vestíbulo de entrada y albergaría además, adosados a su muro sur, seis puestos de abasto. En la planta de 1881 correspondiente al patio principal (fig. 11) se distinguen un total de sesenta y siete locales de venta dispuestos en las galerías del claustro, y otros treinta y dos ubicados en la parte exterior del patio, adosados a los machones de los arcos. En caso necesario, para garantizar un adecuado suministro

${ }^{48}$ En la explicación del plano de Benito León y Canales (fig. 1) que figura en el pequeño abecedario se lee: “ $C$. Corredores cubierta".

49 Sobre el claustro principal y las estancias contiguas, véanse Montero DE EsPINOSA, 1817: 46-47. GonZÁLEZ DE LEÓN, 1973: 527-529. BARRAU, 1881: 28-32.

${ }^{50} \mathrm{Al}$ no cumplir el inmueble los mínimos requisitos como penal, función que había desempeñado desde 1837 , se subasta el 10 de agosto de 1880. Al respecto, véase BARRAU, 1881: 25.

${ }^{51}$ AHM, Colección Alfabética, Mercados, Caja 511, fols. 1-9.

52 Barrau, 1881: 34-37.

${ }^{53}$ La calle, según se recoge en el proyecto, iba a tener 4,40 metros de ancho y 18,40 de largo y sería de titularidad municipal, encargándose el Ayuntamiento de su pavimentación e iluminación (AHM, Colección Alfabética, Mercados, Caja 511, fols. 4-9).

${ }^{54}$ Durante varios años, eso sí, la calle fue dominio particular, pues existía, por lo menos hasta 1899, una cancela que impedía el encedido y apagado de los faroles gestionados por la compañía del gas de Sevilla. Al respecto, véase Collantes, Cruz, Reyes y Rodríguez, 1993: 370.

Arch. esp. arte, LXXXVI, 344, octUBRE-DICIEMBRE 2013, 311-330, ISSN: 0004-0428 


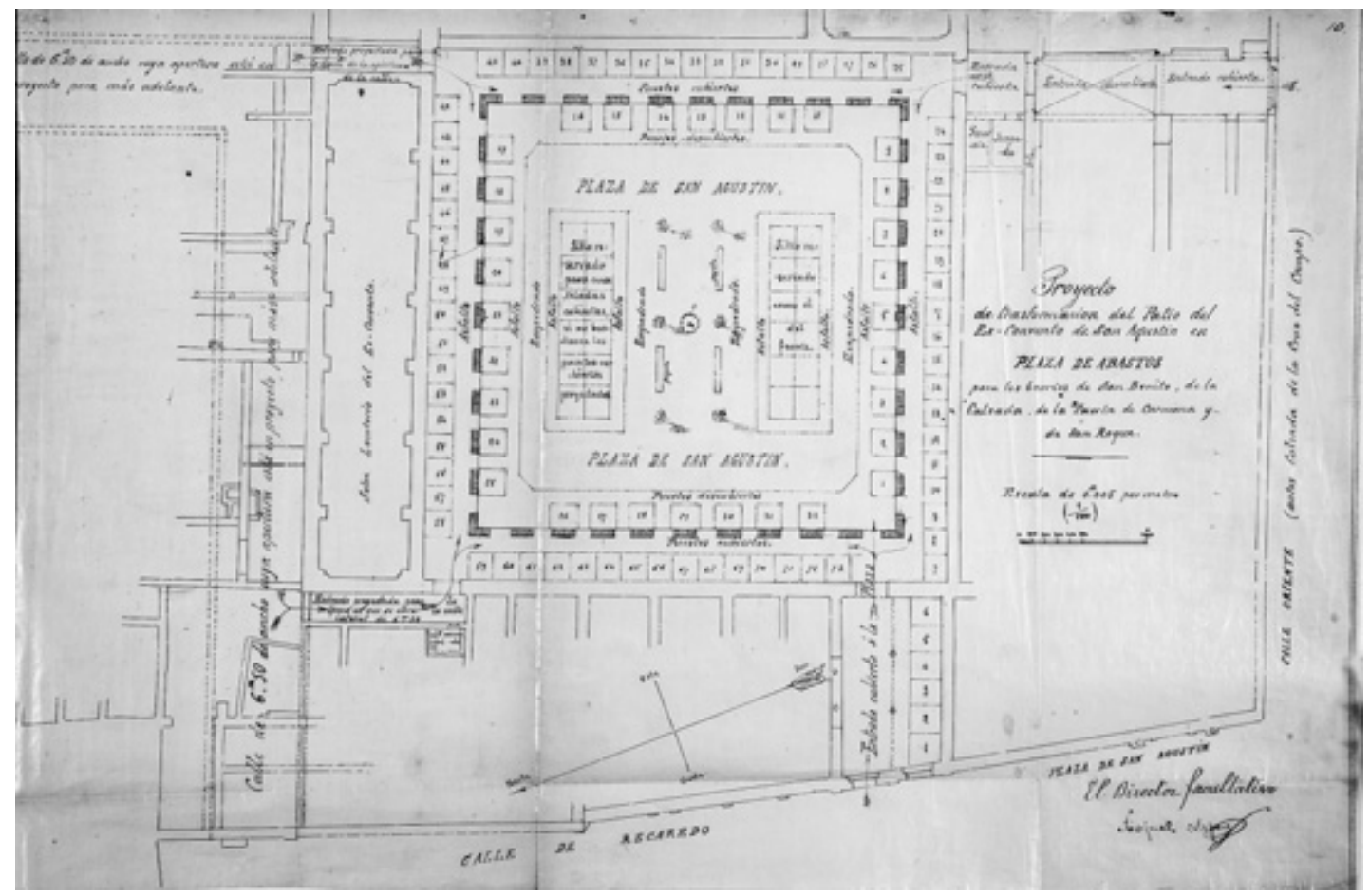

Fig. 11. Proyecto de mercado en el claustro principal de San Agustín. R. López. 1881. Archivo Histórico Municipal de Sevilla.

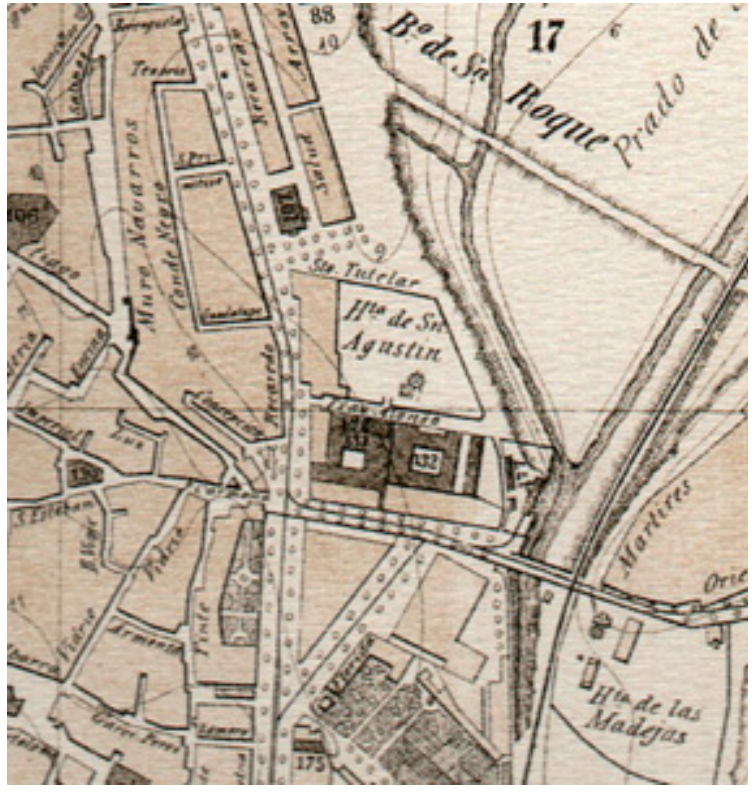

Fig. 12. San Agustín en 1891. A. de Padura y M. de la Vega. Archivo Histórico Municipal de Sevilla. a los vecinos del barrio, se contemplaba la construcción de otras dos cuarteladas en el centro del claustro, cada una con una capacidad de hasta dieciocho puestos de abasto. En el ángulo sur se ubicarían el juzgado del mercado y el cuerpo de guardia, y en el lado norte, por su idónea ventilación, los retretes. Una vez evaluado por Álvarez Millán, arquitecto titular del Ayuntamiento, y tras el informe favorable de la comisión municipal de Obras Públicas, el proyecto de López es aprobado por el Consistorio el 24 de febrero de $1882^{55}$. El mercado se abre al público el 11 de septiembre de 1883 con gran concurrencia de vendedores y compradores ${ }^{56}$. A

${ }^{55}$ AHM, Colección Alfabética, Mercados, Caja 511, fols. 1-9, $20 \mathrm{v}$.

${ }^{56}$ AHM, Colección Alfabética, Mercados, Caja 511, s. fol. Reutilizar el viejo claustro principal como mercado parecía, en principio, una apuesta segura, 
partir de 1896, sin embargo, la reducción de los ingresos de los propietarios del mercado, que cada vez arrendaban menos puestos, y de los vendedores, que perdían clientes, fue progresiva hasta el 31 de diciembre de 1900, fecha en que Caso, White y Barrau deciden disolver la sociedad y cerrar definitivamente la plaza de abastos ${ }^{57}$.

Siguiendo con el análisis del levantamiento realizado por el ingeniero militar Benito León y Canales (fig. 1), cabe precisar que alrededor del claustro principal, donde más adelante, en 1883, como acabo de explicar, se instalará el mercado de San Agustín, se localizan en el plano de 1835 una buena parte de las estancias más funcionales del complejo conventual: situado en paralelo a la crujía norte del edificio claustral, ocupando el emplazamiento habitual en los monasterios medievales desde época carolingia, se localiza el refectorio ${ }^{58}\left(\mathrm{n}^{\mathrm{o}}\right.$ 9), importante estructura arquitectónica del siglo XIV que ha permitido conocer el grado de asimilación del estilo gótico en Sevilla ${ }^{59}$ (figs. 3 y 4). A continuación se disponen las cocinas ${ }^{60}\left(n^{0} 8\right)$ y un gran espacio que era utilizado por los monjes como dormitorio y que, probablemente, estaría dividido en habitaciones mediante sencillos tabiques ${ }^{61}\left(n^{0} 10\right)$. En los ángulos noroeste y nordeste del patio, cerca del refectorio y con directa comunicación con la galería norte, figuran dibujadas dos escaleras de acceso al piso alto: la monumental escalinata, antes referida, que llevaba a la biblioteca; y otra, también impresionante, que todavía se conserva. En el ángulo suroriental del claustro, y en eje axial con la antesacristía y sacristía, piezas ubicadas hacia el sector este del edificio, se emplaza la capilla de Esquivel ${ }^{62}\left(n^{0} 6\right)$, ámbito conocido popularmente como de la Correa de San Agustín por una vieja devoción relacionada con el santo fundador ${ }^{63}$. Esta capilla, de planta cuadrada, tenía comunicación directa con la antesacristía ${ }^{64}\left(n^{\circ} 6\right)$, situada al este, y con las denominadas celdas bajas $\left(\mathrm{n}^{\circ} 7\right)$, localizadas al norte, cuyo corredor, de unos 49 metros de largo, llegaba hasta la huerta del monasterio ${ }^{65}$. No he podido emplazar la capilla de los Vargas, pero se sabe que se localizaba entre el claustro principal y el de los novicios ${ }^{66}$.

La planta de 1835 sitúa el claustro de los novicios ("Patio") en el sector oriental del edificio. Este último patio organiza los espacios comprendidos entre la "Sacristía", pieza rectangular de gran extensión que se localiza, como se ha explicado, a continuación de la antesacristía ${ }^{67}$, y la sala longitudinal que en ese momento también era utilizada como almacén ${ }^{68}\left(n^{0} 5\right)$. Contiguas a este

pues la contigua plaza de San Agustín albergaba en ese momento una gran cantidad de puestos, tinglados y barracones (AHM, Colección Alfabética, Paseos, Caja 540, s. fol.).

57 AHM, Colección Alfabética, Mercados, Caja 511, s. fol.

${ }^{58}$ En la explicación del plano de Benito León y Canales (fig. 1) que aparece a la izquierda del documento gráfico se lee: "9. Refectorio".

${ }^{59}$ Se trata de un gran espacio rectangular de algo más de cuarenta metros de largo por nueve de ancho que consta de siete tramos cubiertos por una bóveda de crucería simple. En el siglo XX, al convertirse los restos del convento en almacén de hierros de la familia Fernández-Palacios, se transformó en oficina y se dividieron sus tramos más occidentales mediante tabiques, creándose también una entreplanta. Sobre esta importante pieza del convento agustino, véase especialmente MartíneZ de Aguirre, 1992: 109-131.

${ }^{60}$ En el abecedario que figura en el plano del ingeniero (fig. 1), a la izquierda, se lee: "8. Cocinas". En 1880, dado el mal estado que presentaban estas dependencias de servicio, se acordó su demolición (BARRAU, 1881: 35).

${ }^{61}$ En la explicación del plano de Benito León y Canales (fig. 1) se lee: "10. Habitaciones".

${ }^{62}$ En el plano del ingeniero (fig. 1), tanto la capilla de Esquivel como la antesacristía son identificadas con el número 6: "6. Claustros de paso y entrada a las celdas en 7".

${ }^{63}$ Fundada en 1409 por fray Rodríguez de Esquivel, religioso del convento, fue reedificada en el siglo XVII (Montero de Espinosa, 1817: 36). La capilla, en 1880, se conservaba en buen estado; justo debajo de ella, se localizaba una extensa bóveda y dos estancias laterales más pequeñas, cada una con su entrada independiente (BARRAU, 1881: 18-19).

${ }^{64}$ Sobre esta dependencia, véase GonZÁlez de LeÓN, 1973: 529.

${ }^{65}$ Barrau, 1881: 32.

${ }^{66}$ Montero de Espinosa, 1817: 41.

${ }^{67}$ Sobre la localización de la sacristía, véase GonZÁLEZ DE LEÓN, 1973: 529.

${ }^{68}$ En el abecedario del plano (fig. 1) se lee: "1.2.3.4.5. Almacenes". 
tercer claustro aparecen delineadas varias estancias de buen tamaño que se identifican como celdas $\left(n^{\circ} 7\right)$, situadas todas ellas en torno a un jardín $\left(n^{\circ} 12\right)$ que centralizaba otra zona de recreo para los monjes.

El levantamiento de Benito León y Canales, sorprendentemente, constata mayores dimensiones para el claustro de los novicios que para el principal. Esta información gráfica, desde luego, resulta desconcertante, porque las fuentes del siglo XIX describen el patio principal como el de mayor tamaño y el más monumental ${ }^{69}$, y las excavaciones de 1984 , además, así lo han confirmado ${ }^{70}$. La extraña divergencia tal vez se deba a un dislate del ingeniero, que no es muy comprensible, la verdad, si se tiene en cuenta que levantar la planta del edificio claustral no parece una operación de gran complejidad y su mayor o menor tamaño, en correspondencia con los otros dos claustros del monasterio, tendría que ser muy evidente para el técnico militar. La posibilidad de que el patio de los novicios fuese, en efecto, de mayores dimensiones que el principal debe ser tenida en cuenta, no obstante, como hipótesis de trabajo, ya que, al fin y al cabo, se están analizando planimetrías antiguas del edificio. Y es que, curiosamente, en el referido plano que Padura y De la Vega levantaron en 1891 (fig. 12), se constata, para ambos claustros, una configuración similar a la delineada por León y Canales: los patios no se sitúan en eje, sino un poco desplazados; hacia el norte, el de los novicios; al sur, el principal. Las dimensiones del claustro de los novicios, sin embargo, no coinciden exactamente porque en el plano de 1891 no se representa tan grande como en el de 1835. Esta diferencia de tamaño, eso sí, tiene una fácil explicación: la apertura de la calle de fray Alonso, que fraccionó el edificio en dos, justo a la altura de la fachada septentrional del refectorio (fig. 4). Basta con trasladar el trazado rectilíneo de esta calle a la planta del ingeniero militar (fig. 1) para comprobar, una vez localizado el refectorio ( $\mathrm{n}^{\circ}$ 9), que la nueva vía, por fuerza, tenía que afectar al patio de los novicios, pues la línea de la calle de fray Alonso, que se ajusta como se ha explicado al muro norte del refectorio, atraviesa las celdas $\left(\mathrm{n}^{\circ} 7\right)$ y amputa un tercio del edificio claustral ("Patio").

Si se estudia la planta de 1835 en su conjunto, se puede apuntar, para concluir el análisis, que en torno a la iglesia y los dos claustros más grandes, piezas que establecen el núcleo estructural del complejo arquitectónico, la distribución espacial parece mejor planificada que en el resto de la clausura, que da la impresión de que se fue ampliando poco a poco mediante la simple adición de dependencias subordinadas a las necesidades concretas de la comunidad, como es habitual en este tipo de construcciones.

Los levantamientos planimétricos de edificios históricos constituyen una forma relevante de expresión científica, y a la vez artística, a la hora de documentar el patrimonio arquitectónico. No cabe duda de su importante papel en el análisis y conocimiento de los procesos transformadores que sufren los edificios o la propia trama urbana de la ciudad ${ }^{71}$, que adquiere mayor significación todavía si apenas se conservan restos históricos. El plano levantado por el ingeniero militar Benito León y Canales ha permitido dar un paso más en el conocimiento del desaparecido monasterio sevillano de San Agustín.

\footnotetext{
${ }^{69}$ En la fuente impresa más antigua que se conserva se mencionan "dos grandes patios rodeados de columnas a que corresponden arcos en el segundo piso", pero no se refieren sus dimensiones concretas (MONTERo de EsPinOsA, 1817: 4647). Décadas más tarde, en 1844, se alude al claustro de los novicios en estos términos: "un segundo patio, no tan grande como el primero" (GoNZÁLEZ DE LEÓN, 1973: 530). BARRAU $(1881: 28,32)$ es el único autor que precisa las dimensiones de los claustros: 33 metros de luz, el principal; y 22,50 metros, el de los novicios.

${ }^{70}$ Campos, Lorenzo, Escudero y Amores, 1985: 361-365.

${ }^{71}$ Sobre la importancia de la cartografía histórica en el estudio y la investigación del patrimonio, véase el monográfico que recientemente ha dedicado al tema el Instituto Andaluz del Patrimonio Histórico: revista ph, $\mathrm{n}^{\mathrm{o}}$ 77, 2011.
} 


\section{BIBLIOGRAFÍA}

Angulo Íñiguez, Diego: Arquitectura mudéjar sevillana de los siglos XIII, XIV y XV, Sevilla, 1932.

Arana de Varflora, Fermín: Compendio histórico descriptivo de la muy noble y muy leal ciudad de Sevilla, Sevilla, 1789.

Barrau, Leoncio: Notas históricas acerca el ex-convento de San Agustín de Sevilla y ex-presidio peninsular, Sevilla, 1881.

Campos, Juan; Lorenzo, José; Escudero, José y Amores, Fernando: "Excavaciones en el antiguo convento de San Agustín (Sevilla)", Anuario Arqueológico de Andalucía, vol. II, 1985.

Capel, Horacio, Sánchez, Joan y Moncada, Omar: De Palas a Minerva, Barcelona, 1988.

Carrillo de Albornoz, Juan: "La Real y Militar Orden de San Fernando y el Arma de Ingenieros (II)", $M e$ morial del Arma de Ingenieros, $\mathrm{n}^{\mathrm{o}}$ 64, 2001.

Collantes, Antonio; Cruz, Josefina, Reyes, Rogelio y Rodríguez, Salvador (Dirs.): Diccionario histórico de las calles de Sevilla, Sevilla, 1993.

Fernández González, Alberto: "Fuentes gráficas para el estudio de tres edificios históricos de Sevilla: las plantas de los conventos de la Santísima Trinidad, San Francisco de Paula y San Pedro de Alcántara", De Arte, $\mathrm{n}^{\circ}$ 11, 2012.

Fernández González, Alberto y Varas Rivero, Manuel: "La arquitectura dibujada: los conventos sevillanos de la Encarnación, el Pópulo y la Merced Calzada según planos del siglo XIX", Archivo Hispalense, ${ }^{\circ}$ 288-290, 2012.

Fernández Rojas, Matilde: Patrimonio artístico de los conventos masculinos desamortizados en Sevilla durante el siglo XIX: Benedictinos, Dominicos, Agustinos, Carmelitas y Basilios, Sevilla, 2008.

Flores, Leandro José: Noticias varias de la collación de San Roque, extramuros de esta ciudad de Sevilla, Sevilla, 1817.

González de León, Félix: Noticia artística de todos los edificios públicos de esta muy noble ciudad de Sevilla, Sevilla, 1973 [1 $1^{\text {a }}$ ed., Sevilla, 1844].

Llorden, Andrés: "Los agustinos en la Universidad de Sevilla", Archivo Hispalense, n 4, 1944.

Martínez de Aguirre, Javier: "El refectorio de San Agustín y la asimilación del Gótico en Sevilla", Archivo Hispalense, $\mathrm{n}^{\circ} 229,1992$.

Montero de Espinosa, José María: Antigüedades del convento Casa Grande de San Agustín de Sevilla, y noticias del Santo Crucifixo que en él se venera, Sevilla, 1817.

Morales, Alfredo: "Hernán Ruiz II, la portada del convento de San Agustín de Sevilla”, Archivo Hispalense, $\mathrm{n}^{\mathrm{o}} 209,1985$.

Murillo Díaz, María Teresa y Campos Carrasco, Juan Manuel: "Excavación de una casa mudéjar en el casco urbano de Sevilla”, en Actas del I Congreso de Arqueología Medieval Española, Zaragoza, 1986.

Ortiz de Zúñiga, Diego: Anales eclesiásticos y seculares de la muy noble y muy leal ciudad de Sevilla, Sevilla, 1988 [ed. facsímil de la ed., Madrid, 1795-1796].

Pérez Cano, María Teresa: Patrimonio y Ciudad. El sistema de los conventos de clausura en el centro histórico de Sevilla, Sevilla, 1996.

Ponz, Antonio: Viage de España, Sevilla, 1972 [ed. facsímil de la ed., Madrid, 1786], vol. IX.

Quesada Gómez, Agustín (coord.): Historia del Arma de Ingenieros, Madrid, 1997.

Revuelta, Manuel: La Exclaustración (1833-1840), Madrid, 2010.

Rojas, Cristóbal de: Teoría y Práctica de Fortificación, conforme a las medidas y defensas de estos tiempos, repartidas en tres partes, Madrid, 1598.

Sánchez Pérez, Emiliano: "La Orden de San Agustín en Sevilla y el patrimonio pictórico de los conventos del Pópulo y San Agustín”, en XI Congreso Internacional de Historia de la Orden de San Agustín, Roma, 2001.

Suárez Garmendia, José Manuel: Arquitectura y urbanismo en la Sevilla del siglo XIX, Sevilla, 1986.

Fecha de recepción: 24-I-2012

Fecha de aceptación: 22-X-2012

Arch. esp. arte, LXXXVI, 344, octUBRE-DICIEMBRE 2013, 311-330, ISSN: 0004-0428 